\title{
Role of Prophylactic Dimenhydrinate Versus Ondansetron as an Adjunct to Dexamethasone on Post-Operative Nausea and Vomiting in Laparoscopic Abdominal Procedures
}

\author{
${ }^{1}$ Sadaf Bukhari, ${ }^{2}$ Aaifa Khalid Niazi, ${ }^{1}$ Syed Mahmood Ali, ${ }^{2}$ Maria Arshad, ${ }^{3}$ Muhammad Taqi \\ ${ }^{1}$ Department of Anesthesia, Shaikh Zayed Medical Complex, Lahore \\ ${ }^{2}$ Department of Anesthesia, Jinnah Hospital, Lahore \\ ${ }^{3}$ Department of Anesthesia, Gulab Devi Hospital, Lahore
}

\begin{abstract}
Introduction: Post-operative nausea and vomiting (PONV) is a common complication in patients undergoing surgery. Anti-emetic prophylaxis is recommended for all high risk patients. Combination therapy is considered superior to single dose prophylaxis however its efficacy in varied laparoscopic abdominal surgical situations has not been investigated. Aims \& Objectives: To compare the post-operative nausea and vomiting with Dimenhydrinate plus Dexamethasone versus Ondansetron plus Dexamethasone in patients following laparoscopic abdominal procedures. Place and duration of study: Operation Theatre, Shaikh Zayed Hospital Lahore, for one year $\left(1^{\text {st }}\right.$ April $2015-31^{\text {st }}$ March 2016). Material \& Methods: 464 patients were placed in two groups of 232 each. Group A received prophylaxis with Dexamethasone $8 \mathrm{mg} \mathrm{I} / \mathrm{V}+$ Dimenhydrinate $50 \mathrm{mg} \mathrm{I} / \mathrm{V}$ and Group B received prophylaxis with Dexamethasone $8 \mathrm{mg} \mathrm{I} / \mathrm{V}+$ Ondansetron $4 \mathrm{mg} \mathrm{I} / \mathrm{V}$. Efficacy was judged with absence of nausea and vomiting in first 24 hours after surgery. Data was analyzed in SPSS version 27. Results: The frequency of nausea was $6 \%$ with Dimenhydrinate while was $9 \%$ with ondansetron. Similarly, vomiting was $18 \%$ vs. $24 \%$ respectively. The efficacy of Dimenhydrinate was $88 \%$ while and Ondansetron achieved efficacy in $65 \%$ cases, which was statistically significant $(\mathrm{p}<0.05)$. Conclusion: The combination Dexamethasone \& Dimenhydrinate was more efficacious in preventing PONV than the combination Dexamethasone \& Ondansetron.
\end{abstract}

Key words: Post-operative nausea and vomiting, Antiemetic prophylaxis, Dexamethasone, Dimenhydrinate, Ondansetron

\section{INTRODUCTION}

$\mathrm{P}$ ost-operative nausea and vomiting (PONV) is the most disturbing and a very commonest problem often after surgery due to anesthesia. PONV may lead to severe patient's anxiety, requirement of nursing care increases, delay in ambulation, also increases pain and in few severe cases, it also badly effects the outcome of the surgery as well as disturb the hemodynamics of patients. ${ }^{1,2}$ It is a troublesome complication and has been the subject of interest of researchers for the past many years. ${ }^{3}$ PONV is an unpleasant emotional experience that provokes both fear and anxiety in the patient. It might instill in the memory of patient for life time. In addition to the fear that it instills in patients, PONV can lead to serious medical complications. ${ }^{4}$ PONV occurs in $20-30 \%$ of patients undergoing surgery. ${ }^{5}$ In high risk patients who receive no prophylaxis the incidence of PONV goes up to 70-
80\%. ${ }^{6,7,8}$ Effective prevention of PONV improves patient satisfaction ratings. All these factors make the prevention and management of PONV a challenge for most anesthesiologists. ${ }^{9}$

The optimal control of PONV is based on three steps. Firstly high risk patients at risk for PONV need to be identified. Secondly such an anesthetic technique should be employed which uses low emitogenic agents and favors use of antiemetogenic agents. Thirdly all patients at risk for PONV should receive antiemetic prophylaxis. ${ }^{6}$ Antiemetic prophylaxis can be provided by pharmacological and non-pharmacological methods. Pharmacological methods include a variety of drugs from different classes. ${ }^{10,11,12}$

Combination therapy of more than one drug is considered far more efficacious as compared to single drug therapy. Drugs with different mechanisms of action should be used in combination. ${ }^{13,14}$ This multi modal approach has 
shown better results when compared with single mode of action prophylaxis. ${ }^{14,15,16,17,18}$

The novelty of our study is this, that it's been done in the face of many risk factors of PONV. Where laparoscopy itself is a risk factor for PONV and in the presence of other PONV risk factors (females, use of nitro oxide, use of opiods, use of volatiles). We have tried to demonstrate Dexamethasone plus Dimenhydrinate combinations' substantial effectiveness which is also very cost effective as per requirement in our country. Other studies are done on tonsillectomy, breast surgeries, and laparoscopic cholecystectomies but not on all types of laparoscopic abdominal procedures. This being another attribute of our study as we have conducted this study in various abdominal laparoscopic surgeries, not just one. So keeping in mind PONV and its challenging outcomes, an effective drug combination is the need of the hour particularly in high risk cases.

\section{MATERIAL AND METHODS}

After taking IRB permission no: 1371, informed consent of 464 patients, 18 years age and above, ASA I \& II, undergoing abdominal laparoscopic surgery was obtained in pre-op area of Shaikh Zayed Hospital Lahore, over a period of one year. The patients were divided into two groups A \& B by lottery method. I/V lines were secured: group A patients were given injection Dexamethasone $8 \mathrm{mg}$ I/V and Inj Dimenhydrinate 50mg I/V. The patients in group B were given Inj. Dexamethasone $8 \mathrm{mg}$ and Inj Ondansetron 4mg I/V.

In the operation theatre standard monitoring was done. Injection Ringer's Lactate $(\mathrm{R} / \mathrm{L})$ was given by 4,2,1 formula respective of their weights. All the patients were given standard general anesthesia. After pre-oxygenation using 100\% Oxygen, anesthesia was given along with injection Fentanyl $1-2 \mathrm{mcg} / \mathrm{kg}$ body weight followed by injection propofol $1-2 \mathrm{mg} / \mathrm{kg}$ body weight. Inj Atracurium was given $0.5 \mathrm{mg} / \mathrm{kg}$ body weight, patient was ventilated for 3 minutes and endotracheal tube was inserted in all patients. Mechanical ventilation was done. Anesthesia was sustained with $50 \%$ oxygen and $50 \%$ nitrous with $1 \%$ isoflurane. Intraoperatively, the muscle relaxation was attained by adding incremental doses of atracurium i.e. $1 \mathrm{mg} / \mathrm{KG}$ on SOS basis. After surgery, anesthesia was stopped and remaining neuromuscular blockade was provoked by applying neostigmine injection along with glycopyrrolate.

To minimize the effects of confounders standardized dose of opioid was used. Also adequate, standardized hydration was done using ringer lactate with the 4,2,1 formula. Inj Fentanyl upto 50mcg I/V was permitted as need for management of post-op pain. After procedure Patients were shifted to Post Anesthesia Care Unit (PACU) where they were monitored for 2 hours and then to ward where they were monitored for $24 \mathrm{hrs}$ by PACU Doctor and nurse on duty.

\section{Statistical analysis:}

Data was fed into SPSS version 17 and analyzed using this program. Chi Square test was used to compare the efficacy in both groups keeping Pvalue $\leq 0.05$ as significant.

\section{RESULTS}

The mean age was $45.65 \pm 9.37$ years. In group A, mean age was $45 \pm 9$ and in group B was $46 \pm 9$ years. In group $\mathrm{A}$, nausea was observed in $14(6 \%)$ cases while in group B, nausea was present in $42(18 \%)$ cases $(p<0.05)$. Within first 2 hours, nausea was observed in $14(6 \%)$ cases in group A while in 27 $(11 \%)$ cases in group B $(\mathrm{p}<0.05)$ while doing first 24 hours, nausea was observed in $0(0 \%)$ cases in group A while in $15(6 \%)$ cases in group B $(p<0.05)$. Similarly, in group A, vomiting was observed in $21(9 \%)$ cases while in group B, vomiting was present in $55(24 \%)$ cases $(\mathrm{p}<0.05)$. Within first 2 hours, vomiting was observed in 14 $(6 \%)$ cases in group A while in $25(11 \%)$ cases in group B ( $>0.05)$ while doing first 24 hours, vomiting was observed in $7(3 \%)$ cases in group A while in $30(12.9 \%)$ cases in group $\mathrm{B}(\mathrm{p}<0.05)$. Efficacy was achieved in $204(88 \%)$ cases in group A while in $152(65 \%)$ cases in group B. The difference between both group was significant $(\mathrm{p}<0.05)$. (Table-1)

\begin{tabular}{|c|c|c|c|}
\hline & Dimenhydrinate & Ondansetron & p-value \\
\hline Age (years) & $45 \pm 9$ & $46 \pm 9$ & \\
\hline \multicolumn{4}{|l|}{ Nausea } \\
\hline Yes & $14(6 \%)$ & $42(18 \%)$ & $<0.001$ \\
\hline No & $218(94 \%)$ & $190(82 \%)$ & \\
\hline Nausea at $2 \mathrm{hrs}$ & $14(6 \%)$ & $27(11 \%)$ & 0.033 \\
\hline $\begin{array}{l}\text { Nausea at 2- } \\
24 \mathrm{hrs} \text {. }\end{array}$ & $0(0 \%)$ & $15(6 \%)$ & 0.0001 \\
\hline \multicolumn{4}{|l|}{ Vomiting } \\
\hline Yes & $21(9 \%)$ & $55(24 \%)$ & $<0.001$ \\
\hline No & $211(91 \%)$ & $177(76 \%)$ & \\
\hline $\begin{array}{l}\text { Vomiting in } \\
\text { first } 2 \mathrm{hrs} \text {. }\end{array}$ & $14(6 \%)$ & $25(11 \%)$ & 0.066 \\
\hline $\begin{array}{l}\text { Vomiting in } \\
2-24 \mathrm{hrs} \text {. }\end{array}$ & $7(3 \%)$ & $30(12.9 \%)$ & 0.0001 \\
\hline \multicolumn{4}{|c|}{ Efficacy achieved } \\
\hline Yes & $204(88 \%)$ & $152(65 \%)$ & $<0.001$ \\
\hline No & $28(12 \%)$ & $80(35 \%)$ & \\
\hline
\end{tabular}

Table-1: Characteristics of patients 


\section{DISCUSSION}

PONV is one of the most common, heavy on the pocket and debilitating complication of general anesthesia. PONV occurs in $20-30 \%$ of patients undergoing surgery. ${ }^{19}$ In high risk patients for PONV who receive no prophylaxis the incidence of PONV goes up to $70-80 \% .^{4,8}$ Although PONV is typically self-limiting, lasting less than 24 hours, the sequences are grave. It can lead to dehydration, electrolyte imbalance, metabolic alkalosis, gastric erosions and aspiration of GI contents with subsequent respiratory problems. ${ }^{20}$ It can also delay oral nutrition and oral drug intake. PONV, thereby delays convalescence and increases hospital stay and cost. ${ }^{21}$

The incidence of PONV depends upon the presence or absence of certain risk factors. Factors that may play a role in development of PONV include sex, age, previous history of PONV, motion sickness and migraines, smoking status, type of surgery, duration of surgery, type of anesthesia, use of opioid analgesics and hydration during surgery. 22,23 These factors can be broadly categorized to "patient factors" which includes females, people who do not smoke, past history of PONV/motion sickness, "Anesthetic Factors" like volatile anesthetic gases, nitrous oxide and use of perioperative opioid analgesics and lastly "Surgical Factors" that include type of surgery and duration of surgery. ${ }^{10}$

The optimal control of PONV is based on three steps. Firstly high risk patients at risk for PONV need to be identified. Secondly such an anesthetic technique should be employed which uses low emitogenic agents and favors use of antiemetogenic agents. Thirdly all patients at risk for PONV should receive antiemetic prophylaxis. ${ }^{6}$ PONV must be controlled effectively especially in high risk patients. Combination therapy of more than one drug is considered far more efficacious as compared to single drug therapy due to its multifactorial origin. Therefore, drug combinations should be used which comprise of drugs that have different mechanisms of action. ${ }^{24,25}$ This multi modal approach has shown better results when compared with single mode of action prophylaxis. The combinations widely used include 5HT-3 receptor antagonist + Dexamethasone, 5HT-3 receptor antagonist + Droperidol, Droperidol + Dexamethasone, Dimenhydrinate + Dexamethasone. ${ }^{26,27,28}$

Despite the presence of a plethora of publications on PONV only little is known on how to treat it.
Our study is another effort to know how to control this distressing PONV, best.

In our study a clinically relevant question about the efficacy of two combination drug regimens was asked. With the knowledge that all these drugs (among them dexamethasone and ondanstron which are considered as gold standard for PONV and a relatively newer drug, dimenhydrinate, which is more widely available and very cost effective) reduce PONV with similar efficacy in patients at high risk, the better of two combinations was sought out. Multimodal interventions are required to control PONV in high risk patients. Dexamethasone is a good drug for combination therapy. It effectively reduces PONV of delayed onset that occurs after 12 hours. When combined with a short acting agent which reduces PONV in the short term $(0-12$ hrs.) the risk of PONV is reduced both in the short term (0-12 hrs.) and in the long term (12-24 hrs).

The combination Dexamethasone plus Ondansetron is a popular one which has been studied extensively and has shown very good results. Ondansetron is effective in early PONV while Dexamethasone controls late PONV. However there are not many studies that have compared it with other combination. Dimenhydrinate is a cheap and widely available drug. It has been shown to be effective in the management of PONV. It hasn't gained as much popularity due to its side effects, sedation, and dry mouth. In theory it should make a good combination with Dexamethasone for the same reasons as Ondansetron. Both of them are effective in prevention of early PONV.

Voight et al., ${ }^{18}$ tried the combination and found results which are equivalent to the combination of dexamethasone plus Ondansetron similar to our study. However no studies have proved superiority of one combination to another which our study hoped to do, in a PONV prone environment. All patients received a standardized anesthetic protocol. Nitrous oxide was used as an analgesic. Although nitrous oxide is a risk factor itself for PONV, it reduced the intraoperative usage of opioids which are a stronger risk factor for PONV. Hydration and opioid doses were standardized to minimize confounding.

Aftab et al. ${ }^{29}$ conducted a study of risk factor assessment for PONV in DOW Medical University Karachi, Pakistan. They concluded that PONV was significantly higher in females, patients with $\mathrm{h} / \mathrm{o}$ PONV or motion sickness and patients undergoing laparoscopic and eye surgery. Our study has addressed two of these risk factors among others 
and observed the effects of anti-emetics in the high risk population.

In India, in year 2014, Bendre and associates, in accordance to our study determined incidence nausea/vomiting, early and delayed with Ondansetron and Dexamethasone. Their results demonstrated for early nausea $26.7 \%$ vs our study $11 \%$. For delayed nausea their result was $23.3 \%$ vs our $6 \%$. For early vomiting they calculated incident of $10 \%$ vs our $24 \%$ and for delayed vomiting their $6.7 \%$ vs our $18 \% .^{30}$

Voigt and associates (2011) carried out a randomized, double blinded, placebo controlled trial. Their results are almost same as of our study. One of their study group received Dimenhydrinate and Dexamethasone, half of this groups' patients received Total intravenous anaesthesia (TIVA) and half of them received volatile anesthesia. They recorded incidence of nausea, emesis or both, in early 0-2 hours and late 2-24 hours post operatively, similar to us. Their result showed significant reduction of PONV $11.4 \%$ with volatiles. Our results showed that the combination of dexamethasone and Dimenhydrinate was significantly better in preventing nausea and vomiting than the Ondansetron and Dexamethasone combination. We observed that Dexamethasone and Dimenhydrinate showed an efficacy of $88 \%$ which is consistent to Voight et al. ${ }^{18}$

Like us Dabbous and fellows (2010) did a randomized study on elective laparoscopic surgeries where they compared efficacy of the combination of Dexamethason and Ondanstron in prevention of PONV. During 24 hours post operatively Dabbous et al observed that no patient had vomiting $(100 \%)$ compared to our $97.6 \% .^{31}$

Imam et al studied the effects of Ondansetron $4 \mathrm{mg}$ plus Dexamethasone with Ondansetron $4 \mathrm{mg}$ alone and placebo in patients undergoing general anesthesia for cesarean section. Episodes of nausea and vomiting were observed in the first 24 hours of extubation. In the combination group $5 \%$ of the patients had PONV. In Ondansetron alone group $22.5 \%$ of the patients had PONV and in the placebo group $52.5 \%$ of patients required antiemetics. The study showed that Ondansetron and Dexamethasone is more effective in preventing PONV with minimal adverse effects, ${ }^{32}$ which is comparable to our study.

Bano and associates studied the effects of Dexamethasone plus Ondansetron with Dexamethasone alone in patients undergoing laparoscopic cholecystectomy. They found that the combination of Dexamethasone plus Ondansetron is more effective in preventing postoperative nausea and vomiting ( $P$ 0.035), close to our $<0.05 .{ }^{17}$

Kothari at al., results are contrasting to ours. They conducted a randomized trial, in patients undergoing laparoscopic cholecystectomy. They observed anti-emetic efficacy of Dimenhydrinate vs Ondansetron. Of the patients receiving Ondansetron post-op vomiting occurred in $6 \%$ versus our $24 \%$ and nausea in $42 \%$ vs our $24 \%$ of the patients. While of the patients who received Dimenhydrinate $29 \%$ vs our $9 \%$ of them vomited and $34 \%$ vs our $42 \%$ of them had nausea. Concluding that ondansetron was superior in controlling vomiting than Dimenhydrinate, in contrast to our results. The discrepancy probably due to our use of these drugs in combination with dexamethasone while Kothari gave them alone. ${ }^{33}$ Contrary to our results Piwko C \& associates showed that for vomiting the Ondansetron group had an efficacy of $45.3 \%$ vs the Dimenhydrinate group's $38.2 \%$ while ours was $75 \%$ for Ondansetron vs a $91 \%$ in Dimenhydrinate group. Piwko evaluated prevention of vomiting only in children whereas our study population were adults. Another factor leading to this dis-similarity in result could be due to the difference of surgical procedure, Piwko chose strabismus surgery while our interest was in abdominal laparoscopic surgeries. ${ }^{34}$

\section{CONCLUSION}

Our research suggests the combination of Dexamethasone and Dimenhydrinate is more efficacious and also more cost effective than the combination of Dexamethason and Ondansterone. This study can be done on a much larger scale including all kinds of surgeries and ASA categories. In light of its promising results Dexamethasone and Dimenhydrinate combination seems to be an excellent arsenal for an anesthetic for better patient care against PONV.

Limitations: PONV was considered as equivalent condition regardless of the surgical procedure duration, or length of anesthesia. Therefore, future studies can be done by standardizing the dose and checking its efficacy on different anesthesia lengths. A further limitation was that although we recorded side effects of the drugs used but we did not include them in our studies. In future we can do the same study but instead of PONV we can observe side effects of these drugs. 


\section{REFERENCES}

1. Cohen MM, Duncan PG, DeBoer DP, Tweed WA. The postoperative interview: assessing risk factors for nausea and vomiting. Anesthesia and analgesia 1994; 78(1):7-16.

2. Gan TJ, Diemunsch P, Habib AS, Kovac A, Kranke P, Meyer TA, et al. Consensus guidelines for the management of postoperative nausea and vomiting. Anesthesia \& Analgesia. 2014; 118(1):85-113.

3. Miller RD, Eriksson LI, Fleisher LA, WienerKronish JP, Cohen NH, Young WL. Miller's anesthesia e-book: Elsevier Health Sciences; 2014.

4. Apfel CC, Philip BK, Cakmakkaya OS, Shilling A, Shi Y-Y, Leslie JB, et al. Who is at risk for postdischarge nausea and vomiting after ambulatory surgery? Anesthesiology: The Journal of the American Society of Anesthesiologists. 2012; 117(3):475-86.

5. Gustafsson U, Scott M, Hubner M, Nygren J, Demartines N, Francis N, et al. Guidelines for perioperative care in elective colorectal surgery: Enhanced Recovery After Surgery (ERAS ${ }^{\circledR}$ ) society recommendations: 2018. World journal of surgery. 2019; 43(3):659-95.

6. Cao X, White PF, Ma H. An update on the management of postoperative nausea and vomiting. Journal of anesthesia 2017; 31(4):617-26.

7. D'souza N, Swami M, Bhagwat S. Comparative study of dexamethasone and ondansetron for prophylaxis of postoperative nausea and vomiting in laparoscopic gynecologic surgery. International Journal of Gynecology \& Obstetrics. 2011; 113(2):124-7.

8. Apfel CC, Korttila K, Abdalla M, Kerger H, Turan A, Vedder I, et al. A factorial trial of six interventions for the prevention of postoperative nausea and vomiting. New England journal of medicine. 2004; 350(24):2441-51.

9. Kranke P, Eberhart LH. Postoperative nausea and vomiting: rational algorithms for prevention and treatment based on current evidence. Anasthesiologie, Intensivmedizin, Notfallmedizin, Schmerztherapie: AINS 2009; 44(4):286-94; quiz 95.

10. Sbaraglia F, Saviani M, Timpano JM, Rossi M. Postoperative nausea and vomiting as a cause of tracheal injury: an underestimated lifethreatening adverse event? British journal of anaesthesia. 2019;123(3):e457-e8.
11. Helms RA, Quan DJ. Textbook of therapeutics: drug and disease management: Lippincott Williams \& Wilkins; 2006.

12. Chisholm-Burns MA, Wells BG, Schwinghammer TL. Pharmacotherapy principles and practice: McGraw-Hill; 2016.

13. Rother C. Post-Operative Nausea \& VomitingUse of Anti-Emetic Agents in Anaesthesia. Scottish Universities Medical Journal 2012;1(1).

14. Smith HS, Cox LR, Smith EJ. 5-HT3 receptor antagonists for the treatment of nausea/vomiting. Ann Palliat Med 2012; 1(2):115-20.

15. Mihara T, Tojo K, Uchimoto K, Morita S, Goto T. Reevaluation of the effectiveness of ramosetron for preventing postoperative nausea and vomiting: a systematic review and metaanalysis. Anesthesia \& Analgesia 2013; 117(2):329-39.

16. Som A, Bhattacharjee S, Maitra S, Arora MK, Baidya DK. Combination of 5-HT3 antagonist and dexamethasone is superior to 5-ht3 antagonist alone for ponv prophylaxis after laparoscopic surgeries: a meta-analysis. Anesthesia \& Analgesia. 2016; 123(6):1418-26.

17. Bano F, Zafar S, Aftab S, Haider S. Dexamethasone plus ondansetron for prevention of postoperative nausea and vomiting in patients undergoing laparoscopic cholecystectomy: a comparison with dexamethasone alone. J Coll Physicians Surg Pak. 2008; 18(5):265-9.

18. Voigt M, Fröhlich CW, Waschke KF, Lenz C, Göbel $U$, Kerger $H$. Prophylaxis of postoperative nausea and vomiting in elective breast surgery. Journal of clinical anesthesia. 2011; 23(6):461-8.

19. Hung L-W, Chou M-Y, Liang C-K, Liu K, Chou Y-M. Being older as a risk factor for vomiting in those undergoing spinal anesthesia. Journal of Clinical Gerontology and Geriatrics. 2012; 3(2):68-72.

20. Strong M, Merritt CCM. Pharmacology and Antibiotics. Surgical Critical Care and Emergency Surgery: Clinical Questions and Answers. 2018: 97-108.

21. Feinleib J, Kwan LH, Yamani A, Davidson A. Postoperative nausea and vomiting. UpToDate Waltham (MA): UpToDate 2018.

22. Hijazi EM, Edwan H, Al-Zoubi N, Radaideh H. Incidence of Nausea and Vomiting After FastTrack Anaesthesia for Heart Surgery. Brazilian journal of cardiovascular surgery. 2018; 33(4):371-5.

23. Gwinnutt M, Gwinnutt CL. Clinical anaesthesia: John Wiley \& Sons; 2016. 
24. Bayter M, Peña P, Marquez M, CárdenasCamarena L, Macias A, Rubio J, et al. Incidence of postoperative nausea and vomiting when total intravenous anaesthesia is the primary anaesthetic in the ambulatory patient population. Ambul Surg. 2018; 24:8-11.

25. Kranke P, Wilhelm W, Eberhart L. Management of Postoperative Nausea and Vomiting (PONV). Enhanced Recovery After Surgery: A Complete Guide to Optimizing Outcomes. 2020:195-202.

26. Tjia I, Dalton M, Watcha MF. Management of postoperative nausea and vomiting in pediatric patients. Postoperative Nausea and Vomiting: a practical guide. 2016:119-30.

27. Chen X, Qin Y, Li S, Lei H, Wu X, Shu L. Efficacy of 5-HT3 receptor antagonists (ondansetron) vs dopamine receptor antagonists (droperidol) for preventing postoperative nausea, vomiting and headache: a meta-analysis. Pteridines. 2019; 30(1):146-52.

28. Bang SR, jin Kim H, Ahn EJ, Choi HR, Kim $\mathrm{KW}$, Ko MJ, et al. Effect of total intravenous anesthesia and prophylactic 5-HT3 receptor antagonist on postoperative nausea and vomiting after gynecologic laparoscopic surgery: A prospective, randomized controlled study. Rawal Medical Journal 2017; 42(1):73-7.

29. Aftab S, Khan AB, Raza G. Assessment of risk factors for postoperative nausea and vomiting. J Coll Physicians Surg Pak 2008; 18(3):137-41.

30. Bendre R, Karthik S, Potli S, Madhusudhana R. A comparative study of ondansetron with dexamethasone and granisetron with dexamethasone for prevention of postoperative nausea and vomiting following abdominal surgeries under general anaesthesia. WJPPS 2015; 4(3):605-20.

31. Dabbous AS, Jabbour-Khoury SI, Nasr VG, Moussa AA, Zbeidy RA, Khouzam NE, et al. Dexamethasone with either granisetron or ondansetron for postoperative nausea and vomiting in laparoscopic surgery. Middle East $\mathbf{J}$ Anesthesiol 2010; 20(4):565-70.

32. Imam SM, Imam SM, Mufti TM, Bhatti AH, Faridi MA. Efficacy of balanced antiemesis for prophylaxsis againt post operative nausea and vomiting [PONV]: comparative study of ondansetron and dexamethasone versus ondansetron alone, Pak. Armed Forces Med J 2004; 54(2):185-90.

33. Kothari S, Boyd W, Bottcher M, Lambert P. Antiemetic efficacy of prophylactic dimenhydrinate (Dramamine) vs ondansetron (Zofran). Surgical endoscopy.2000;14(10):926-9.

34. Piwko C, Lasry A, Alanezi K, Coyte PC, Ungar WJ. Economic evaluation of ondansetron vs dimenhydrinate for prevention of postoperative vomiting in children undergoing strabismus surgery. Pediatric Anesthesia.2005;15(9):755-61

\section{The Authors:}

Dr. Sadaf Bukhari

Senior Registrar, Department of Anaesthesia, Shaikh Zayed Hospital, Lahore.

Dr. Aaifa Khalid, Senior Registrar, Department of Anaesthesia, Jinnah Hospital, Lahore.

Dr. Syed Mahmood Ali

Associate Professor,

Department of Anaesthesia,

Shaikh Zayed Hospital Lahore

Maria Arshad

Senior Registrar,

Department of Anaesthesia, Jinnah Hospital, Lahore.

Dr. Muhammad Taqi

Senior Registrar,

Department of Anaesthesia,

Gulab Devi Hospital, Lahore.

\section{Corresponding Author:}

Dr. Sadaf Bukhari

Senior Registrar,

Department of Anaesthesia,

Shaikh Zayed Hospital, Lahore.

E-mail: dr.sadaf.bukhari@gmail.com 